\title{
INCORPORATING TEAM-EFFECTIVENESS AS A LEARNING OBJECTIVE in the Design Project Within a Technical Core Course
}

\author{
Greg Evans $^{a}$, Patricia Sheridan ${ }^{a}$, Doug Reeve ${ }^{a}$, Maygan McGuire ${ }^{b}$, Kristina Minnella $^{a}$, Estelle Oliva- \\ Fisher $^{a}$, Lydia Wilkinson ${ }^{b}$, and Todd McAlary ${ }^{b}$ \\ Institute for Leadership Education in Engineering ${ }^{\mathrm{g}}$, Faculty of Applied Science and Engineering ${ }^{\mathrm{b}}$, \\ University of Toronto, greg.evans@utoronto.ca
}

\begin{abstract}
CHE 230 'Environmental Chemistry' is a core Chemical Engineering course offered in the spring semester of second year. A central element of the course is the 'Environmental Consulting Engineering' project, a full semester design project that is executed in five-member teams. The acquisition of teamwork and group-leadership skills has been one of the project learning objectives for about five years; the related instructional components have been refined every year. This presentation will describe the theoretical foundation and methods used to teach team-effectiveness as part of this design project.

Instruction of team skills has been based on two conceptual frameworks. A leadership styles framework examines the preferences of individual students and helps students see how these styles are manifested within a team. This framework allows students to identify their leadership style preferences and more importantly, recognize the strengths of others, and styles that may be missing from their team. A team-effectiveness framework helps students examine organizational, relational and communication behaviours evident within their team, and thereby helps students to recognise where they do, or do not, tend to contribute. These two frameworks provide students with a shared vocabulary, along with a basis to observe and understand their team experiences that can then be used to promote learning and structured reflection.

The instructional components used are an introductory lecture on team effectiveness, a two-hour team formation workshop, a reflection done by the team after the first major deliverable and an individual reflection at the end of the course. These components are intended to direct students from recognizing aspects of team-effectiveness, towards seeing deficiencies in their team or their individual contributions. The students are then guided towards finding practical tools and techniques that they can use to become more effective at different aspects of teamwork.
\end{abstract}

Keywords: design projects, teamwork, leadership instruction

\section{INTRODUCTION}

CHE 230 'Environmental Chemistry' is a core technical course offered to second year Chemical Engineering students at the University of Toronto. This course examines applied chemistry in relation to environmental systems. The first half of the course examines chemical equilibrium in relation to natural waters. The topics covered include: alkalinity, the interfacial partitioning of organic compounds, formation of metal complexes, and the redox behaviour of metals in different waters. The second half of the course examines chemical kinetics in relation to atmospheric chemistry. The topics covered include: ozone depletion, urban smog, acid rain, atmospheric aerosol, and climate science. This content is instructed through descriptive lectures and quantitative tutorials, in which the students work in teams.

Central to this course is the Environmental Consulting Project worth 25\% of their final course grade. Students complete this project in self-managed and self-selected teams of five. Over the 13 week term, the teams each prepare a proposal in a mock competitive-bid for a site assessment to determine the extent of chemicals in one of three scenarios (soil, water or air contamination). The iterative nature of the project provides numerous feedback and learning opportunities. Each year, the most technically competent and professional group from each scenario is selected to present their final proposal to the class (and relieved of the final proposal submission). The implementation of this integrative project and its impact on students was previously described [1]. This article describes the instruction of team-effectiveness within the context of this course in 2011 and 2013.

\section{PROJECT DESCRIPTION}

Figure 1 summarizes the progression of the project throughout the term. Embedded within the structure of the project are multiple opportunities for obtaining feedback from the instructors, which enable an iterative learning process. Student teams respond to a 
"request for proposal" sent out by a fictitious company, "Wallberg International". The project thereby progresses through a series of milestones, namely a letter of intent, preliminary proposal, interim client meeting, formal client meeting and final proposal.

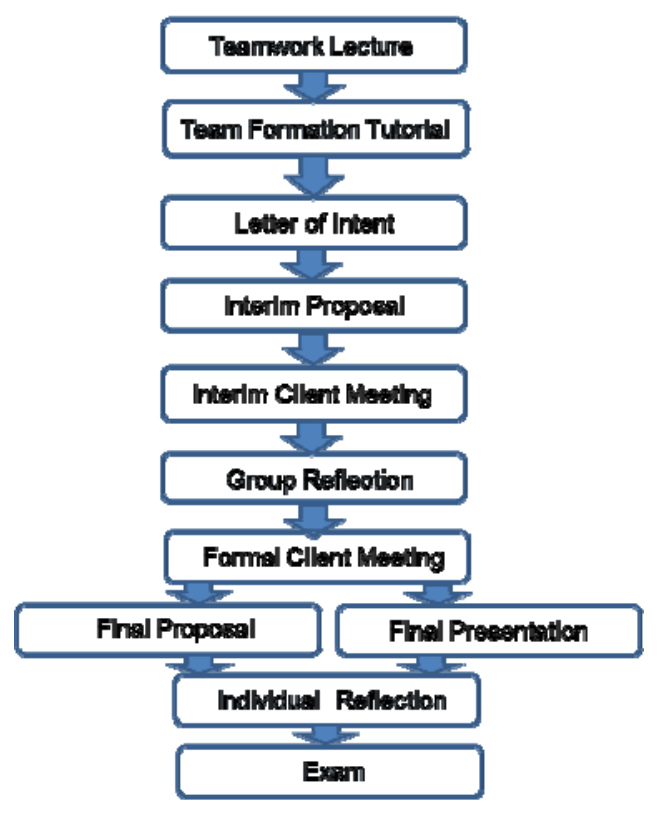

Fig. 1. Project Process; highlighted in blue are team effectiveness related course components

\section{TEAM EFFECTIVENESS INSTRUCTION}

\subsection{Learning Objectives}

Embedded within this structure are multiple opportunities for the students to learn teamwork related skills. The desired learning objectives are that students be able to:

1) Identify the preferred style of teammates and describe how these styles contribute to a team.

2) Identify organisational, relational and communication related behaviours and describe how these contribute to a team.

3) Explain the roles of trust and conflict in effective teamwork.

4) Identify and apply tools and techniques to make an engineering team more effective.

\subsection{Conceptual Frameworks}

Two conceptual frameworks are used to scaffold the team effectiveness learning throughout the project. The Team Effectiveness Framework (TEF) examines "how" students tend to contribute to teams, in terms of their organisational, relational and communication competencies. The Leadership Styles Framework (LSF) examines "who" the students are, in terms of their preferred ways of interacting. The LSF helps students see themselves, and others, in terms of their assertiveness and relational tendencies. Before forming teams, the students complete the brief 18question inventory associated with the LSF [2]. The student's preferred style is thereby identified based on where they land within four quadrants (Fig. 2).

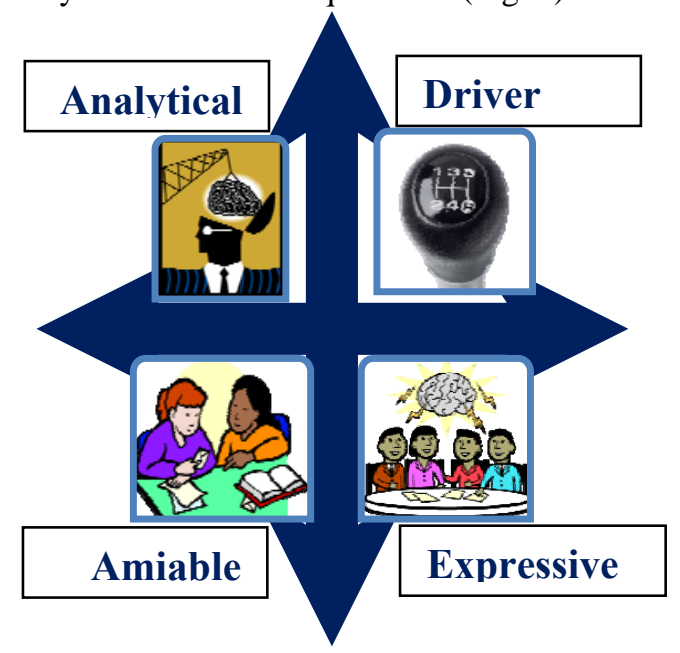

Fig. 2. The four preferred leadership styles used to describe individual contributions and team interactions

Three additional learning objectives are associated with the LSF, which are that students be able to:

5) Perceive how they and their teammates interact and contribute in teams.

6) Use a shared vocabulary to describe these ways of contributing to shared leadership

7) See and adjust when a role is missing in a team.

The TEF helps students identify and describe organizational, relational and communication behaviours evident within their team, and how these contribute to making a team effective. .The students can thereby recognise the ways they do, or do not, tend to contribute to making a team effective, as described in detail in another presentation [3]. Eighteen behaviours are introduced to the students (see example in Table 1). This TEF is then used in the team formation tutorial and to help guide a reflection at the end of the course.

Table 1: Illustrative behaviours from the team effectiveness framework 


\begin{tabular}{|l|}
\hline \multicolumn{1}{|c|}{ Behaviour: Did your team? } \\
\hline Organisational Aspects \\
\hline Encourage progress to meet goals and deadlines \\
\hline Deliver work on time \\
\hline Relational Aspects \\
\hline Build the trust of teammates \\
\hline Motivate others on the team to do their best \\
\hline Communication Aspects \\
\hline Actively listen to teammates \\
\hline Raise contentious issues in a constructive way \\
\hline
\end{tabular}

\subsection{Team Formation Lecture and Tutorial}

The first learning opportunity occurs before the teams were formed. A lecture is given on effective teamwork. The lecture describes the importance of establishing a foundation of trust, the value of different perspectives, and constructive conflict. The students are introduced to the LSF during this lecture and complete the associated inventory, which only takes a few minutes. The students then participate in a two hour team formation tutorial, delivered as a workshop.

In 2013, this workshop had the following structure. Students were first asked to go to the four corners of the room, based upon their birth month, and to form teams of five that contained at least one of each of the four leadership styles. The students each completed a guided reflection on their past contributions in teams, guided by the TEF, and then discussed this with their new teammates. A debrief with the class was facilitated in which students were asked to identify tools and techniques they might use to promote the positive behaviours framed within the TEF (e.g. how would you raise a contentious issue? How would you make sure work is delivered on time?). Students typically responded more readily to questions relating to the organisational than relational behaviours.

The students participated in a "challenge" to replicate a hidden Lego structure that only one member could view at a time, with no verbal communication allowed. This challenge required them to coordinate their activities under time-limit induced stress. This activity was followed by a debrief that was related back to the roles that different students took on, the leadership styles present within their teams, the role of trust, and whether the structure was seen from different perspectives.

The students then formed their own permanent teams for the project, based on i) which of the three topics they wanted to work on, and ii) maximising the diversity of the leadership styles within their teams. Some students gave weight to this second criteria, but divisions along cultural and gender lines were still apparent. Students in these teams may well have attempted to increase diversity in leadership styles, while giving priority to working with a limited subgroup of friends with whom they identified based on shared cultural, language and gender identities. The teams then competed in a second challenge requiring them to build the tallest "egg supporting" structure they could with straws and tape. This was followed by a class debrief, again drawing from the two frameworks.

The final step was a visioning exercise where the teams were asked to imagine and discuss how they could build the most effective team they have ever been on, and how they could produce the best possible product.

Students enjoyed the team formation lecture and tutorial and reported that it helped them get to know their teammates and motivated them to make their team effective (Table 2).

Table 2: Confidential student evaluation of the 2013 team formation lecture and tutorial. Student replies were on a seven point Likert scale with values of 5 to 7 indicating a positive to very positive response.

\begin{tabular}{|l|c|}
\hline Evaluation Statement & $\begin{array}{l}\text { Proportion of } \\
\text { Responses } \geq \mathbf{5}\end{array}$ \\
\hline $\begin{array}{l}\text { a) I better understand my } \\
\text { leadership style }\end{array}$ & $66 \%$ \\
\hline $\begin{array}{l}\text { b) I better understand how I } \\
\text { contribute in teams }\end{array}$ & $59 \%$ \\
\hline $\begin{array}{l}\text { c) I learned skills to make the } \\
\text { teams I am in more effective }\end{array}$ & $56 \%$ \\
\hline $\begin{array}{l}\text { d) I will place more effort into } \\
\text { making my team effective }\end{array}$ & $88 \%$ \\
\hline $\begin{array}{l}\text { e) I was able to get to know my } \\
\text { team members }\end{array}$ & $94 \%$ \\
\hline $\begin{array}{l}\text { f) I am looking forward to the } \\
\text { consulting engineer project }\end{array}$ & $75 \%$ \\
\hline
\end{tabular}

The comments of the students during tutorial provided some indication of learning achieved. For example, students used the language of the LSF:

- To discuss their own success and areas of improvement: "I am more Expressive, so I was getting really excited and loud while others in my group were not"

- As a starting point to give their peers effective feedback using common language: "You are a Driver and it was good that you started to read the instructions at the beginning of the exercise to get us going"

- To reflect on how behaviors that might have been a source of negative conflict could actually have a positive outcome: "Our team had many people who were Drivers and Expressives that made us really want to do the task quickly. At first we saw 
that one member was doing things very slowly but because he was an Analytical he ended up catching and fixing a lot of the mistakes we made."

Using the TEF, students were able to pick out areas their team focused on, and areas they ignored. Many groups indicated that the organizational aspects came easily, while the relational and communication aspects needed more focus. Some students were better able to point to the strengths of their team by using the TEF. Students began to pick out which of the 18 behaviours in the TEF they were using and how these translated into practice. Overall, using the LSF and TEF, and translating these into tools that could be used, helped students to take leadership within these self-managed teams into their own hands.

\subsection{Team and Individual Reflections}

Two reflections were completed by the students so as to help them consolidate their thinking on team effectiveness. The first reflection was completed as a team at the course midpoint (Fig.1). This was an unguided reflection: students were asked to describe their team performance and effectiveness. The majority of the responses addressed organisational aspects such as the need to have tighter internal deadlines, more frequent and structured meetings and more quality control in advance of the submission of deliverables. There were some comments relating to the need for more effective internal communication and coordination, rather than each member working on a different part of the project and hoping that these sections could be stitched together just prior to the deadline. There was little mention of the relational aspects.

The second reflection was completed individually by students at the end of the project, after submission of their final report. It was structured around the LSF and TEF. The students were asked to reflect on whether their contributions were mostly consistent with their preferred leadership style or if they had needed to adjust to the styles of their teammates. The students were also asked to comment on the team's strengths and weaknesses in relation to the TEF, and to identify tools and techniques that had contributed to building this strength or that could have been used to address these weaknesses.

\subsection{Other Assessments}

Additional input was solicited at different stages of the course. Each team was asked to provide the LSF and Myers Briggs Type Indicators (MBTI) composition of their team. Briefly, the MBTI categorises personalities into 16 types, based on four "dichotomies": here people get their energy (E vs. I), how they seek information (S vs. N), how they make decisions (T vs. F) and their preference for structure ( $\mathrm{J}$ vs. P). This data was reported by the team in a way that did not require the students to reveal which information was associated with each individual member. There was some interesting mapping of the LSF on the MBTI (Table 3). For example, a majority of "Drivers" and minority of "Analyticals" were extroverts. Other differences were not consistent between the two classes.

Table 3: Leadership styles and MBTI types for the classes of 2013 and 2011. Values that were more than $15 \%$ lower or higher than the class average, respectively, are in in blue and red show. Values in purple differed between the two classes.

\begin{tabular}{|l|c|cccc|}
\hline $\mathbf{2 0 1 3}$ & Class & E & N & T & J \\
\hline Class & $100 \%$ & $49 \%$ & $49 \%$ & $57 \%$ & $68 \%$ \\
\hline Expressive & $28 \%$ & $65 \%$ & $48 \%$ & $43 \%$ & $65 \%$ \\
Driver & $18 \%$ & $60 \%$ & $47 \%$ & $80 \%$ & $87 \%$ \\
Analytical & $30 \%$ & $20 \%$ & $56 \%$ & $68 \%$ & $76 \%$ \\
Amiable & $23 \%$ & $58 \%$ & $42 \%$ & $42 \%$ & $47 \%$ \\
\hline
\end{tabular}

\begin{tabular}{|l|c|cccc|}
\hline $\mathbf{2 0 1 1}$ & Class & E & N & T & J \\
\hline Class & $100 \%$ & $51 \%$ & $57 \%$ & $47 \%$ & $83 \%$ \\
\hline Expressive & $28 \%$ & $80 \%$ & $67 \%$ & $40 \%$ & $87 \%$ \\
Driver & $30 \%$ & $50 \%$ & $47 \%$ & $50 \%$ & $81 \%$ \\
Analytical & $29 \%$ & $19 \%$ & $65 \%$ & $52 \%$ & $81 \%$ \\
Amiable & $13 \%$ & $64 \%$ & $36 \%$ & $57 \%$ & $86 \%$ \\
\hline
\end{tabular}

The class of 2013 was distinctive in terms of the unusually high representation (23\%) of the more relationally oriented "Amiables" and low representation (18\%) of the more assertive "Drivers". Further, there was a lower percentage of "Judging" type personalities than in the 2011 class. The students completed the MBTI using a free on-line inventory, thus the reliability of the data is questionable. The intention was to increase awareness of personality types as a learning exercise, rather than to conduct an accurate assessment. However, the experience of teaching these two classes was very different. In 2013, participation, attendance and engagement were higher, and perhaps as a result, they performed better on the midterm and final exam.

Students were also asked to evaluate their learning in the consulting project and team formation exercises through the anonymous course evaluation completed at the end of the course. Statements related to the project, assessed on a seven point Likert scale, read: 
1. The consulting project helped me improve my technical knowledge of environmental engineering.

2. The consulting project helped me improve my communication skills.

3. The consulting project helped me to become more professional.

The outcomes of the course evaluation will be available in tie for the presentation.

A “Bonus" exam question, worth up to an extra $5 \%$, asked students to answer two of three questions:

a) Describe two concepts or methods you learnt from CHE230 that will help you to make future engineering teams that you work on more effective.

b) Identify two of the four leadership styles and describe what they contribute to teams.

c) Explain the roles of trust and conflict in teamwork.

These low-level questions assessed whether students had acquired basic conceptual knowledge associated with the desired team-effectiveness learning outcomes. The responses were generally good to very good and most students received all five marks. These replies were coded as they were graded; the coding had no influence on the grading. Conflict was seen as positive more often than negative, but many students still described conflict as something to be avoided (e.g. "conflict cannot be avoid in teams but sometimes it creates a better/stronger relationship with your teammates"). Most students could describe the four styles and the descriptions of all four styles were mostly positive. Many students described the "Driver" as the "leader" as this was the person who drove things get done.

Organisational aspects were favoured in the responses for questions a) and c). The methods described for question a), were often about scheduling and meeting deadlines. For question c), trust was most often described in terms of trusting your teammates to deliver their work. This emphasis on the organisational aspects may be because these are seen as more tangible and therefore easier to grasp than relational behaviours. Students may see and hence value organisation as the aspect that is most closely linked with the quality of the product, and hence grades. The emphasis on organisation may be amplified by the competitive and time constrained design of the project. Overall, the emphasis on organisation suggests that some teams were struggling to develop into an effective team and continued to approach the project as a group of individuals.

\section{CONCLUSIONS}

Incorporation of team effectiveness related learning objectives is achieving some of the outcomes set out in the design of this course. A basic structure of learning elements has been developed that should be transferable to other courses. This structure includes the use of two frameworks, a workshop and lecture on teams and team formation, reflections, and assessment components. This structure starts to address the pedagogical questions of: What to teach? How to teach it? How to assess the outcomes?

Combining the instruction of conceptual elements though the introductory lecture and experiential workshop-based tutorial has been very well received by the students. The two frameworks help students develop mental models with which to think about team effectiveness, as exhibited through the shared vocabulary that they develop. This vocabulary is evident throughout the course, from the comments in the initial tutorial to the answers to questions on the final exam. These mental models will hopefully support continued learning in upper year courses.

More generally, the two frameworks are helping students develop a shared awareness of how an individual can contribute in different ways to making a team effective. This awareness empowers the students and helps them to switch their paradigm from teamwork as a passive experience to be endured, to teamwork as an active experience that they can, and should, proactively shape. This switch will ideally lead students to realise that there should be leadership from all members in self-managed teams, and that they individually need to participate actively in building the team experience.

Progress was made towards achieving this goal of students taking ownership in proactively shaping their team. Further, the students were motivated by the practical experience of the mock competitive bid process because they saw the practical value in future career opportunities. However, the students still value organisational aspects of team effectiveness over relational aspects, as was evident in the replies on the exam questions. Presumably students link organisational performance directly to grades, the primary goal in the minds of many students. Opportunities exist to increase the value that students place on relational aspects, if we can shift the student's focus from the immediate priority of grades, to longer term learning. Thus a clearer link between the development of relational skills and future career opportunities needs to be made. Relationships will likely be as, if not more important, to their eventual career success and positive impact on society. 
The described structure for teaching team effectiveness is a start, and it will be refined and improved as other teaching tools in development at the University become available. Most immediately, TEF is being incorporated into a web based teaching tool, to allow individualised $360^{\circ}$ feedback and provide interactive learning exercises and activities. This web based tool will hopefully be ready in a pilot form the next time the course is offered, in 2014.

\section{References}

[1] Evans G.J., M. McGuire, D, Tihanyi "Using Environmental Consulting as a Team Design Project: Role Play to reality”. Proc. Canadian Engineering Education Conference, Kingston Jun 7-9, 2010

[2] Sheridan, P.K. D. Reeve, and G. Evans, "Student perceptions and use of an inventory to facilitate learning of individual team-effectiveness" Canadian Engineering Education Association, Montreal, Canada, 2013.

[3] Bolton, Robert, Grover-Bolton Dorothy, People Styles at Work: Making Bad Relationships Good and Good Relationships Better Amacon, New York, 1996. 